\title{
OPTIMIZATION OF OPERATIONAL PARAMETERS OF FOAM SIZING PROCESS FOR COTTON YARNS BASED ON PLACKETT-BURMAN EXPERIMENT DESIGN
}

\author{
Bo Zhu, Jianli Liu, Weidong Gao \\ Jiangsu Engineering Technology Research Center for Functional Textiles, Jiangnan University, Wuxi, China, 214122 \\ gaowd3@163.com
}

\begin{abstract}
:
This study was aimed at investigating the process optimization of foam sizing for cotton yarns. In this work, effects of major foam-sizing process factors including size concentration, blowing ratio, stirring speed, pre-wetting temperature, pre-drying temperature, squeezing pressure and drying temperature were studied on the hairiness (more than $3 \mathrm{~mm}$ ) and abrasion resistance of foam-sized yarns. The combination of Plackett-Burman, steepest ascent path analysis and Box-Behnken design were adopted to optimize the foam-sizing process of cotton yarns. Results revealed that size concentration, blowing ratio and squeezing pressure were significant factors that affected the hairiness and abrasion resistance. Optimum hairiness and abrasion resistance were obtained when the cotton yarns were sized at size concentration of $19.33 \%$, blowing ratio of 4.27 and squeezing pressure of $0.78 \mathrm{kN}$. The theoretical values and the observed values were in reasonably good agreement and the deviation was less than $1 \%$. Verifcation and repeated trial results showed that it has good reproducibility and imparts the foam sizing process of cotton yarns.
\end{abstract}

\section{Keywords:}

Foam sizing, cotton yarns, Plackett-Burman design, Box-Behnken design, process optimization

\section{Introduction}

In recent decades, foam technology such as foam dyeing [1-4] and foam finishing [5-8] rapidly developed in the textile industry. Meanwhile, foam sizing has been studied for 30 years. In 1980, Warren and Robert proved that the properties of warps sized using foam were equivalent or superior to those of similar warps sized conventionally $[9,10]$. Namboodri indicated that foam sizing of cotton yarns realized energy savings and increased production speed, and less bridging of warps and reduced warp hairiness were the anticipated benefits [11]. Trauer and Vialon not only discussed the differences between foam sizing and conventional technology, but also studied the influences of size concentration on the quality of warp sizing $[12,13]$. Vernekar showed that the energy consumption using foam sizing was almost half that of conventional sizing approach, while the sizing qualities of the two methods had no appreciable difference. [14]. Shah and Gandhi compared the differences of energy consumption between the devices of foam and conventional sizing, and illustrated that the foam-sizing technology needed more fundamental research in the realization of industrialization promotion [15]. Berk pointed out that the technology of foam sizing made the size film on the yarn surface more uniform and the hairiness lower [16]. In 1988, Xiong Yan studied the foaming performances of sizing materials and analyzed the main factors influencing the foamablity of size liquor [17]. In 1999, Zhou Xiaohong found that the adhesive, foaming agent and the adhesive concentration played an important role in the foam-sizing technology [18]. In 2014, Weidong Gao [19, 20] in Jiangnan University developed foam sizing into industrial application and studied the sizing effects of foam-sizing and warp pre-wetting combined process.
This paper investigated the impacts of size concentration, blowing ratio, stirring speed, pre-wetting temperature, predrying temperature, squeezing pressure, drying temperature on hairiness and abrasion resistance of sized yarns as the response values. Firstly, Plackett-Burma design was used to select significant factors in foam-sizing process. Then, steepest ascent experiment and Box-Behnken design response surface method were adopted to evaluate the optimal range and to determine the optimum levels.

\section{Experimental details}

\subsection{Materials}

Oxidized starch and polyacrylic acid (XP-C) were supplied by Fengyang Co. Ltd (China); lauryl sodium sulfate was purchased from Sinopharm Chemical Reagent Co. Ltd. Cotton 19.4 tex single yarns were purchased from Yancheng Yueda cotton spinning Co. LTD.

\subsection{Methods}

\subsubsection{Plackett-Burman design}

Plackett-Burman design worked on time-saving and manpower-consumption to analyze the significant parameters with respect to their main effects and not the interaction effects between the various parameter constituents. The required numbers of this experimental design runs were very few, which led to saving of time, chemicals, glassware and manpower. In this paper, Plackett-Burman design was 
applied for twelve trails in order to select the significance of seven factors grouped as process factors of foam sizing (size concentration $X 1$, blowing ratio $X 2$, stirring rate $X 3$, pre-wetting temperature $X 4$, pre-drying temperature $X 5$, squeezing pressure $X 6$, drying temperature $X 7$, and $X 8, X 9$, $\mathrm{X} 10$ and $\mathrm{X} 11$ were dummy factors). Each factor was tested at two levels coded as $(-1)$ for lower level and $(+1)$ for higher level, as it is depicted in Table 1. The Design-Expert version 8.0.6 was used for experimental design analysis and data processing.

\subsubsection{Steepest ascent experiment}

The steepest ascent experiment was performed to approach the center points of each factor for further optimization study. The path of steepest ascent (descent) was the direction in which the response increased the most. The step-size was determined based on process knowledge and practical considerations. This method was used by modelling and analyzing the relationships between several independent variables and response variable(s). Effective response surface equations can be built when the response variables infinitely approach the optimum values.

\subsubsection{Box-Behnken Design}

A statistical Box-Behnken design was used as a means of adequately optimizing significant factors. To systematically evaluate the main and interaction variables that affected foam sizing process of cotton yarns, Box-Behnken statistical design was selected for the optimization study and the Design Expert 8.0.6 software was used for experimental design analysis and data processing.

\subsubsection{Statistic analysis}

To verify the reliability of the results, the experiments were carried out in triplicate and averages and standard deviations were obtained.

\section{Results and Discussion}

\subsection{Plackett-Burman analysis}

Design table (code) and response values of Placket-Burman experiment was presented in Table 2. Effects of factors on hairiness index (R1) and abrasion resistance (R2) are depicted in Table 3.

Table 1 Factors and levels used in Plackett-Burman design

\begin{tabular}{|c|c|c|c|}
\hline \multirow{2}{*}{ Codes } & \multirow{2}{*}{ Factors } & \multicolumn{2}{|c|}{ Levels } \\
\hline & & -1 & +1 \\
\hline $\mathrm{X} 1$ & Size concentration (\%) & 10 & 20 \\
\hline $\mathrm{X} 2$ & Blowing ratio & 5 & 10 \\
\hline X3 & Stirring rate $(r / m i n)$ & 350 & 750 \\
\hline $\mathrm{X} 4$ & Pre-wetting temperature $\left({ }^{\circ} \mathrm{C}\right)$ & 85 & 95 \\
\hline $\mathrm{X} 5$ & Pre-drying temperature $\left({ }^{\circ} \mathrm{C}\right)$ & 60 & 80 \\
\hline $\mathrm{x} 6$ & Squeezing Pressure (kN) & 0.5 & 1.5 \\
\hline $\mathrm{X} 7$ & Drying temperature $\left({ }^{\circ} \mathrm{C}\right)$ & 100 & 120 \\
\hline $\mathrm{X} 8 ; \mathrm{X} 9 ; \mathrm{X} 10 ; \mathrm{X} 11$ & Dummy factors & - & - \\
\hline
\end{tabular}

Table 2 Design table (code) and response values of Placket-Burman experiment

\begin{tabular}{|c|c|c|c|c|c|c|c|c|c|}
\hline Run & $\mathbf{X 1}$ & $\mathbf{X 2}$ & $\mathbf{X 3}$ & $\mathbf{X} 4$ & $\mathbf{X 5}$ & $\mathbf{X 6}$ & $\mathbf{X 7}$ & $\mathbf{R} \mathbf{R}$ & $\mathbf{R} 2$ \\
\hline 1 & 1 & -1 & -1 & -1 & 1 & 1 & -1 & 2.69 & 261.2 \\
\hline 2 & 1 & 1 & -1 & 1 & 1 & -1 & 1 & 3.17 & 222.1 \\
\hline 3 & -1 & 1 & 1 & 1 & -1 & -1 & -1 & 8.06 & 102.3 \\
\hline 4 & 1 & -1 & 1 & 1 & 1 & -1 & -1 & 1.65 & 297.6 \\
\hline 5 & -1 & -1 & -1 & 1 & -1 & 1 & 1 & 7.36 & 116.8 \\
\hline 6 & -1 & 1 & 1 & -1 & 1 & 1 & 1 & 9.14 & 93.6 \\
\hline 7 & 1 & -1 & 1 & 1 & -1 & 1 & 1 & 2.78 & 256.2 \\
\hline 8 & -1 & -1 & 1 & -1 & 1 & -1 & 1 & 6.36 & 147.4 \\
\hline 9 & 1 & 1 & -1 & -1 & -1 & -1 & 1 & 3.28 & 219.3 \\
\hline 10 & -1 & 1 & -1 & 1 & 1 & 1 & -1 & 9.35 & 89.7 \\
\hline 11 & 1 & 1 & 1 & -1 & -1 & 1 & -1 & 3.92 & 192.5 \\
\hline 12 & -1 & -1 & -1 & -1 & -1 & -1 & -1 & 6.34 & 142.3 \\
\hline
\end{tabular}


Factors evidencing P-values of less than 0.05 were considered to have significant effects on the response values and defined as a remarkable factor, and were therefore selected for further optimization studies. Stirring rate $\mathrm{X} 3$, pre-wetting temperature $X 4$, pre-drying temperature $X 5$ and drying temperature $X 7$ had p-value more than 0.05 and were excluded from the following optimization due to significantly smaller contributions to the hairiness of sized yarns. The factors displaying significant positive effects on hairiness were size concentration $(p=0.0001)$, blowing ratio $(p=0.0002)$ and squeezing pressure $(p=0.0008)$, and the corresponding confidence level respectively were $85.97,9.62$ and 4.13. Similarly, for the analysis of abrasion resistance, the significant factors to $\mathrm{R} 2$ were size concentration $(p=0.0001)$, blowing ratio $(p=0.0011)$ and squeezing pressure $(p=0.0281)$, and the corresponding confidence level were $82.17,12.87$ and 3.97 , respectively; the other factors had no significant effects on R2.

\subsection{Steepest ascent analysis}

The steepest ascent path was analyzed to find the appropriate direction of changing factors, increasing the levels of each factor response values. Design table of the steepest ascent experiment with hairiness and abrasion resistance are displayed in Table 4. According to the effect of the three factors - the direction of size concentration, blowing ratio and squeezing pressure - a set of experimental runs were designed. As shown in Table 4, the smallest value of hairiness appeared in the fourth step and the largest value was also located in step 4. Comprehensively, the optimum value areas of process parameters were $10-20 \%$ of size concentration, $4-8$ of blowing ratio and $0.50-1.00 \mathrm{kN}$ squeezing pressure.

\subsection{Box-Behnken Analysis}

A sequence of Box-Behnken experiments were performed that would yield the most information about the factors and their interactions in as less experiments as possible (17 runs). A 3 factor and 3 level factorial Box-Behnken experimental design technique was carried out around the optimum to locate true optimum levels of size concentration, blowing ratio and squeezing pressure. Factors and levels of BBD experiment were shown in Table 5 and Design table and results of BBD experiment were shown in Table 6.

An interactive second order polynomial model was utilized to evaluate both response factors. The polynomial equations generated by design expert is described as equation (1) and (2):

$$
\begin{aligned}
& Y 1=218.30+76.91 X 120.19 \times 28.12 \times 65.85 \times 1 X 2 \\
& +0.025 X 1 X 6+2.78 X 2 X 6+0.30(X 1)^{2} 8.33(X 6)^{2}
\end{aligned}
$$

$$
\begin{aligned}
& Y 2=3.28-2.36 \mathrm{X} 1+0.22 \mathrm{X} 2+0.51 \mathrm{X} 6-0.24 \mathrm{X} 1 \mathrm{X} 2 \\
& -0.15 \mathrm{X} 1 \mathrm{X} 6+0.34 \mathrm{X} 2 \mathrm{X} 6+0.33(\mathrm{X} 2)^{2}-0.0052(\mathrm{X} 6)^{2} \\
& +0.31(\mathrm{X} 1)^{2} \mathrm{X} 6-0.29 \mathrm{X} 1(\mathrm{X} 2)^{2}
\end{aligned}
$$

The two equations represented the quantitative effect of factors (X1, X2, and X6) and their interactions on the response values. The values of $X 1, X 2$ and $X 6$ were substituted in the equation to obtain the theoretical values of $Y 1, Y 2$. The model equations were tested for significance and their variance was analyzed. The $p$-value of both equations was less than 0.05 , which indicated a significant effect of independent factors on the response values. Hence, it assured that the current model provided a satisfactory fit to the data.

Table 3 Effects of factors on hairiness and abrasion resistance

\begin{tabular}{|c|c|c|c|c|c|c|}
\hline \multirow{2}{*}{ Factors } & \multicolumn{3}{|c|}{ Hairiness } & \multicolumn{3}{c|}{ Abrasion resistance } \\
\cline { 2 - 7 } & P-value & Confidence (\%) & Standard Error & P-value & Confidence (\%) & Standard Error \\
\hline X1 & 0.0001 & 85.97 & 0.059 & 0.0001 & 82.17 & 0.029 \\
\hline X2 & 0.0002 & 9.62 & 0.059 & 0.0011 & 12.87 & 0.029 \\
\hline X3 & 0.7109 & 0.07 & 0.059 & 0.3476 & 0.04 & 0.029 \\
\hline X4 & 0.4144 & 0.05 & 0.059 & 0.4734 & 0.54 & 0.029 \\
\hline X5 & 0.4279 & 0.04 & 0.059 & 0.0840 & 3.97 & 0.029 \\
\hline X6 & 0.0008 & 4.13 & 0.059 & 0.0281 & 0.029 \\
\hline X7 & 0.9149 & 0.06 & 0.059 & 0.4479 & 0.02 & 0.029 \\
\hline
\end{tabular}

Table 4 Design table of steepest ascent experiment with hairiness and abrasion resistance

\begin{tabular}{|c|c|c|c|c|c|}
\hline $\begin{array}{c}\text { Number of } \\
\text { steps }\end{array}$ & $\begin{array}{c}\text { Size } \\
\text { concentration (\%) }\end{array}$ & Blowing ratio & $\begin{array}{c}\text { Squeezing } \\
\text { Pressure (kN) }\end{array}$ & $\begin{array}{c}\text { Hairiness } \\
\text { (pieces/m) }\end{array}$ & $\begin{array}{c}\text { Abrasion } \\
\text { resistance(times) }\end{array}$ \\
\hline 1 & 5 & 2 & 0.25 & 9.27 & 68.6 \\
\hline 2 & 10 & 4 & 0.50 & 4.84 & 145.8 \\
\hline 3 & 15 & 6 & 0.75 & 3.42 & 2.89 \\
\hline 4 & 20 & 8 & 1.00 & 4.03 & 224.3 \\
\hline 5 & 25 & 10 & 1.25 & 202.6 \\
\hline
\end{tabular}


Table 5. Factors and levels of BBD experiment

\begin{tabular}{|c|c|c|c|c|}
\hline \multirow{2}{*}{ Codes } & \multirow{2}{*}{ Factors } & \multicolumn{3}{|c|}{ Code level } \\
\cline { 3 - 5 } & & $\mathbf{- 1 . 0 0}$ & $\mathbf{0 . 0 0}$ & $\mathbf{1 . 0 0}$ \\
\hline $\mathrm{X} 1$ & Size concentration (\%) & 10 & 15 & 20 \\
\hline $\mathrm{X} 2$ & Blowing ratio & 4 & 6 & 8 \\
\hline X6 & Squeezing pressure $(\mathrm{kN})$ & 0.50 & 0.75 & 1.00 \\
\hline
\end{tabular}

Table 6. Design table and results of BBD experiment

\begin{tabular}{|c|c|c|c|c|c|}
\hline Run & $\mathbf{X 1}$ & $\mathbf{X 2}$ & $\mathbf{X 6}$ & $\begin{array}{c}\text { Y1 } \\
\text { Hairiness (pieces/m) }\end{array}$ & $\begin{array}{c}\text { Y2 } \\
\text { Abrasion resistance(times) }\end{array}$ \\
\hline 1 & 0.00 & 1.00 & 1.00 & 7.89 & 118.7 \\
\hline 2 & 1.00 & -1.00 & 0.00 & 4.67 & 168.3 \\
\hline 3 & 0.00 & 0.00 & 0.00 & 3.28 & 218.3 \\
\hline 4 & 0.00 & -1.00 & 1.00 & 2.11 & 141.5 \\
\hline 5 & 0.00 & 0.00 & 0.00 & 6.02 & 183.4 \\
\hline 6 & -1.00 & 0.00 & -1.00 & 2.98 & 218.3 \\
\hline 7 & -1.00 & 1.00 & 0.00 & 3.28 & 218.3 \\
\hline 8 & -1.00 & 0.00 & 1.00 & 3.27 & 218.3 \\
\hline 9 & 0.00 & 0.00 & 0.00 & 3.28 & 129.6 \\
\hline 10 & 1.00 & 1.00 & 0.00 & 6.97 & 236.8 \\
\hline 11 & 0.00 & 0.00 & 0.00 & 3.22 & 218.3 \\
\hline 12 & 1.00 & 0.00 & -1.00 & 3.28 & 279.1 \\
\hline 13 & 0.00 & 0.00 & 0.00 & 1.60 & 139.9 \\
\hline 14 & -1.00 & -1.00 & 0.00 & 1.94 & 210.6 \\
\hline 15 & 1.00 & 0.00 & 1.00 & 6.35 & 309.8 \\
\hline 16 & 0.00 & 1.00 & -1.00 & 3.56 & 1.54 \\
\hline 17 & 0.00 & -1.00 & -1.00 & & \\
\hline
\end{tabular}

Additionally, a series of the three-dimensional (3D) frameworks for the optimization of parameters of foam sizing process for cotton yarns were further depicted to study the interaction and quadratic effects of the three factors on the response values. The 3D response surface illustrations for hairiness and abrasion resistant are presented in Figure 1 and 2, respectively.

In Figure 1(a), (b) and (c), size concentration, blowing ratio and squeezing pressure had significant correlations. When size concentration (X1) was increased from 10 to $20 \%$, the hairiness (Y1) also increased to a large extent. Figure 1 (b) expressed that a less value of $Y 1$ could be obtained when $X 2$ ranged from 4-8. While $X 6$ level was increased from 0.50 to $1.00, Y 1$ had a trend of first increasing and then decreasing.

In Figure 2(a), (b) and (c), the correlations among size concentration, blowing ratio and squeezing pressure were significant. The abrasion resistance (Y2) had an increasing trend as size concentration (X1) increased from10 to $20 \%$. A lower value of $Y 2$ could be obtained with an $\mathrm{X} 2$ ranging from
4-8, when $X 1$ and $X 6$ were fixed. $Y 2$ tended to increase first and then decrease, when $X 6$ level ranged from 0.50 to 1.00 .

In summary, higher size concentration was favorable to increase the abrasion resistance and decrease hairiness. Whereas, both abrasion resistance and hairiness decreased as the blowing ratio increased. The squeezing pressure should be controlled in a certain scope. Too high or too low squeezing pressure was not conducive in increasing the yarn properties.

In order to optimize and analyze the experimental results, the optimization objectives were defined as: the hairiness was less than 2 pieces $/ \mathrm{m}$ and the abrasion resistance was greater than 290 times. To verify the validity of the optimization results, predicted and experimental response values led by optimal parameters after optimization with response surface method were shown in Table 7. The theoretical (predicted) values and the observed values were in reasonably good agreement and the deviation was less than $1 \%$, indicating that the optimization results proved the validity of the model. 


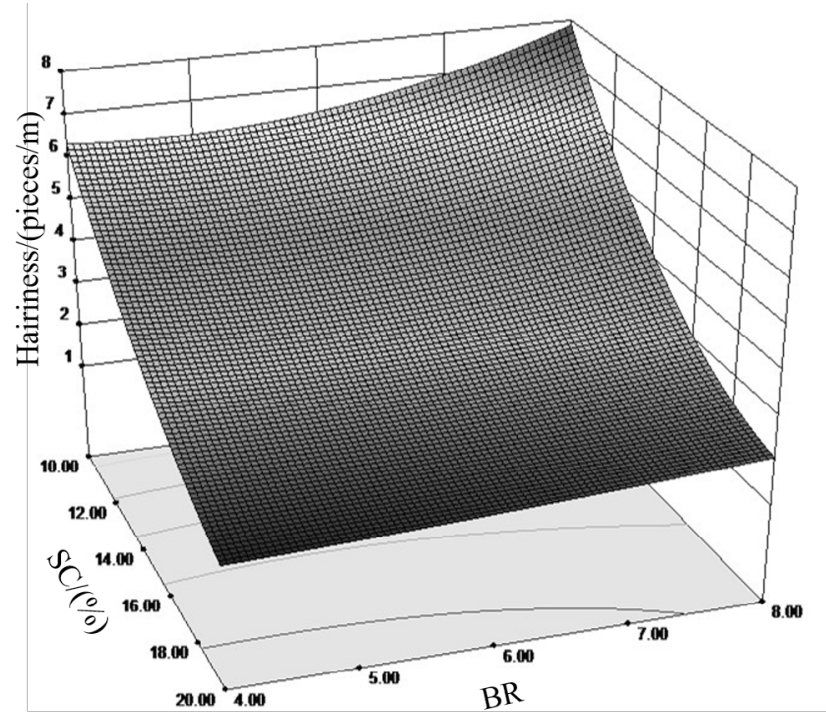

(a) Effects of Size concentration and blowing ratio on hairiness

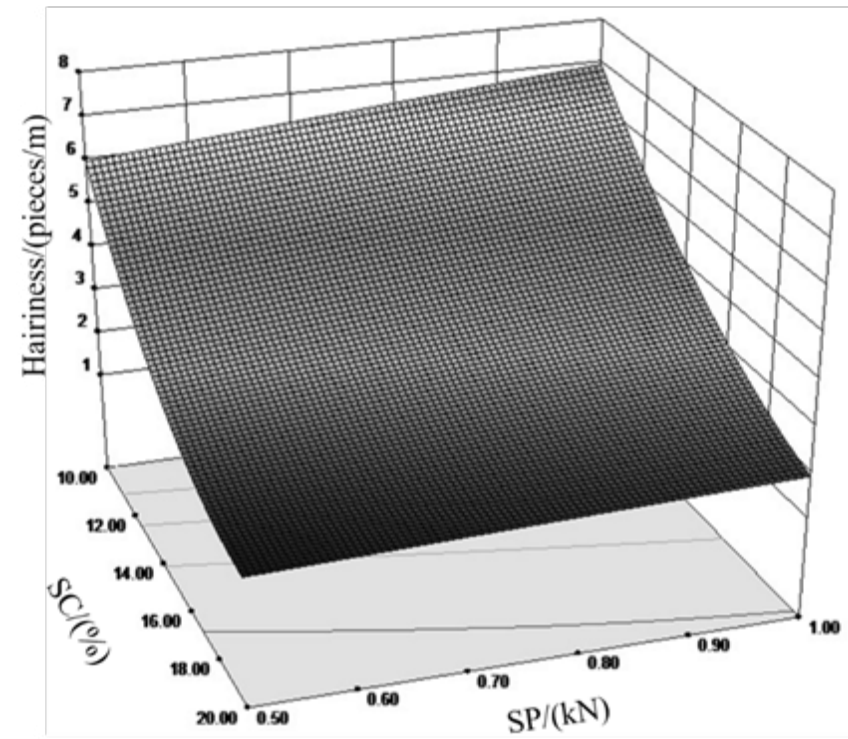

(b) Effects of size concentration and squeezing pressure on hairiness

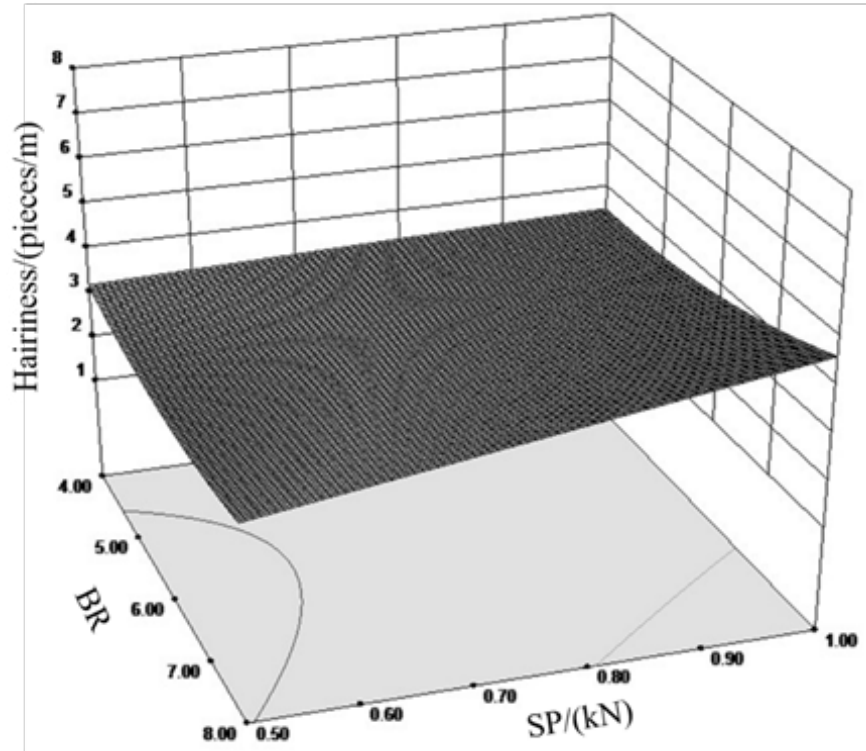

(c) Effects of squeezing pressure and blowing ratio on hairiness

Figure 1 The $3 \mathrm{D}$ response surface illustrations for hairiness

http://www.autexrj.com/

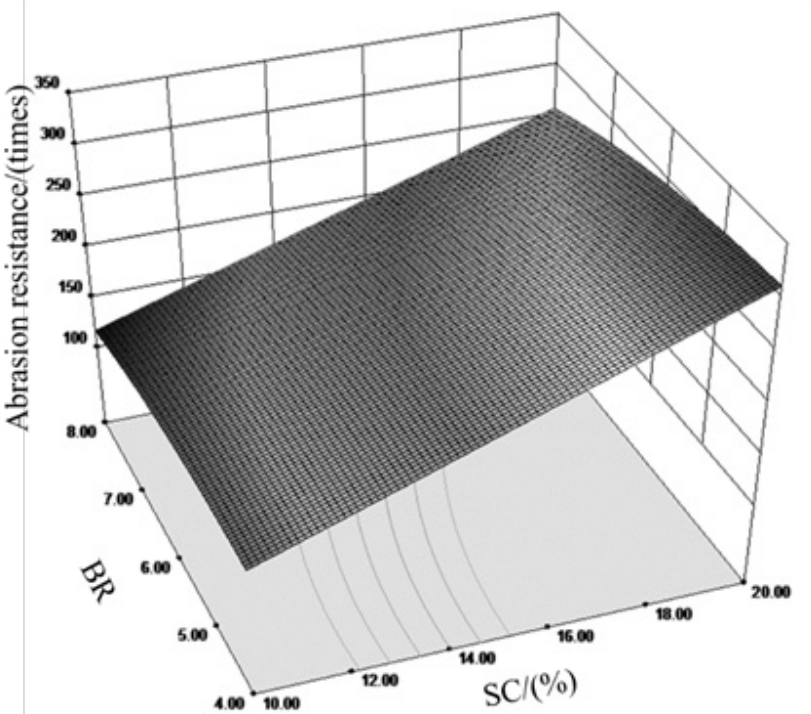

(a) Effects of size concentration and blowing ratio on abrasion resistance

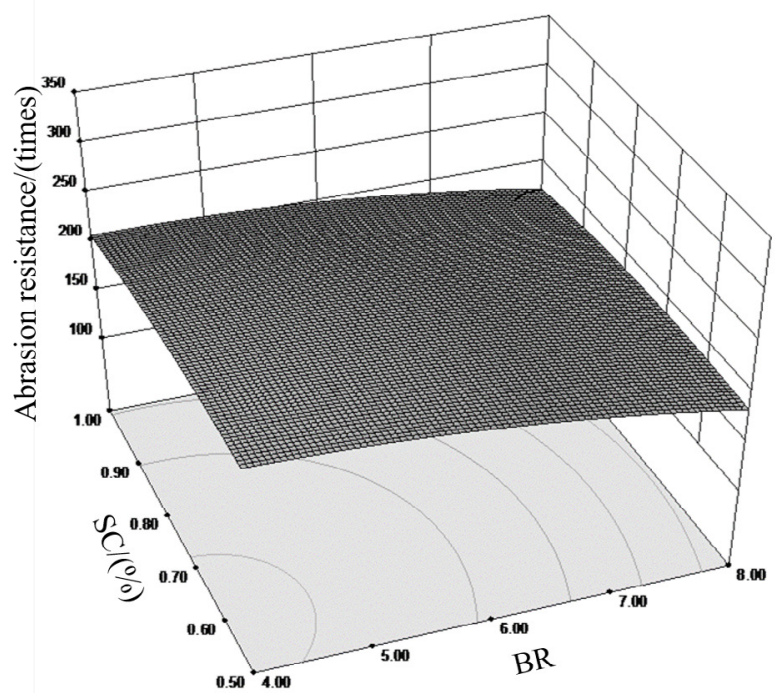

(b) Effects of size concentration and squeezing pressure on abrasion resistance

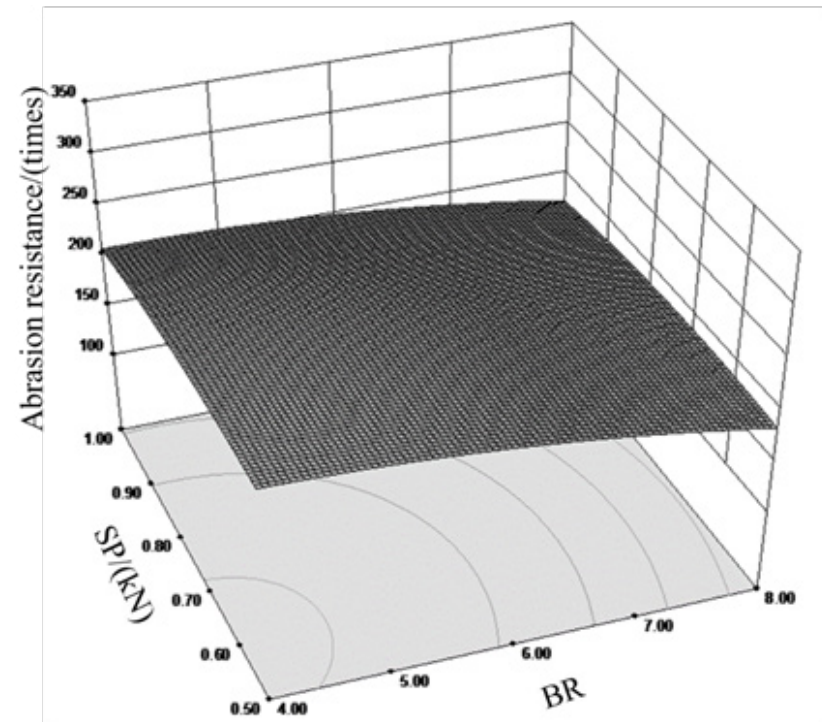

(c) Effects of squeezing pressure and blowing ratio on abrasion resistance

Figure 2 The 3D response surface illustrations for abrasion resistant 
Table 7. Predicted and experimental response values led by optimal parameters after optimization with response surface method

\begin{tabular}{|c|c|c|c|c|c|c|}
\hline \multirow{2}{*}{$\begin{array}{c}\text { Size } \\
\text { concentration } \\
(\%)\end{array}$} & Blowing ratio & $\begin{array}{c}\text { Squeezing } \\
\text { pressure (kN) }\end{array}$ & \multicolumn{2}{|c|}{ Hairiness (pieces/m) } & \multicolumn{2}{|c|}{ Abrasion resistance(times) } \\
\cline { 4 - 7 } & & Predicted & Experimental & Predicted & Experimental \\
\hline 19.33 & 4.27 & 0.78 & 1.72 & 1.81 & 297.9 & 311.3 \\
\hline
\end{tabular}

\section{Conclusions}

This paper, using Plackett-Burma (PB) design, investigated the impact of operational parameters of the foam sizing process, including the size concentration, blowing ratio, stirring speed, pre-wetting temperature, pre-drying temperature, squeezing pressure and drying temperature, on the outcome of foam sizing. Yarn hairiness and abrasion resistance were employed as the response values to identify significant factors influencing the foam sizing quality. Then, the steepest ascent experiment with hairiness and abrasion resistance was used to evaluate the optimal range of significant factors. Box-Behnken design response surface method was employed to optimize the factors that were found to be significant. Size concentration, blowing ratio and squeezing pressure were significant factors that affected the foam sizing quality of cotton yarns. The response values reached the maximum level when the values were set at size concentration of $19.33 \%$, blowing ratio of 4.27 , and squeezing pressure of $0.78 \mathrm{kN}$. The three statistic approaches were useful to optimize the foam sizing for cotton yarns, greatly reduce the harmful hairiness and enhance the abrasion resistance, and provided a scientific basis for further investigation in the sizing industry.

\section{ACKNOWLEDGEMENTS}

The author would like to acknowledge funding from the innovation project of Jiangsu Graduate Education (No. CXZZ13_0749), the scientific research project of Jiangnan University (No. JUDCF13025), the prospective joint research project of Jiangsu Province (No. BY2015019-07), the independent innovation and the transformation of scientific and technological achievements project of Shandong Province (No. 2014CGZH0205) and the priority academic development program of Jiangsu higher education institutions (PAPD).

\section{References}

[1] Perkins W., Walker R. (1982). Foam Sizing. Textile Research Journal, 9, 547-554.

[2] Lu K., Zhang X. L., Zhao Y.L., Wu Z.L. (2010). Removal of color from textile dyeing wastewater by foam separation. Journal of Hazardous Materials, 182, (1-3), 928-932.

[3] Yu H., Wang Y.L., Zhong Y., Mao Z.P., Tan S. S. (2014). Foam properties and application in dyeing cotton fabrics with reactive dyes. Coloration Technology, 130(4), 266-272.
[4] Julieta S. N., Guilherme C. M., Carlos J. S., Reis C., Reis E. $L$. (2011). Polyurethane foams for the removal of the Direct Red 80 and Reactive Blue 21 dyes in aqueous medium. Desalination, 281, 55-60.

[5] Li K., Zhang J., Gong J. (2014) Wrinkle-resistant finish of foam technology for cotton fabric. Journal of Industrial Textiles, 43(4), 525-535.

[6] Baker K., Bryant G., Camp J., Kelsey B. (1982). Foam Finishing Technology. Textile Research Journal, 1982, 52(6), 395-403.

[7] Namboodri C., Duke M. (1979). Foam Finishing of CottonContaining Textiles. Textile Research Journal, 49(3), 156162.

[8] Gregorian, Bafford, Namboodri. (1979). The utilization of foams in wet processing of textiles. American Chemical Society, 107, 155-174.

[9] Perkins W., Walker R. (1984). Some Observations on Foam Sizing. Textile Chemist \& Colorist, 4, 37-39.

[10] Perkins W., Walker R. (1980). Foam sizing can halve energy costs. Textile World, 130(3), 55-62.

[11] Namboodri C. (1986). Foam Sizing of Cotton and Blend Yarns: Slashing Trials. Textile Research Journal, 2, 87-92.

[12] Trauter, Vialon. (1986). Aspects of Foam Sizing. Textiletrieb, 104(3), 33-41.

[13] Trauter, Vialon. (1987). State of Foam Sizing. Textile Asia, 18(4), 97.

[14] Vernkar. (1992). Foam Sizing-Perspectives and Limitaions. Man-made Textiles in India, 35(2), 51-52.

[15] Shah, Gandhi. (1990). Technique of Foam Sizing. Indian Textile Journal, 100(2), 184-185.

[16] Beck. (1989). Foam Technology in Yarn Sizing. Textile Praxis Intertional, 623.

[17] Yan X., Zhao J. (1988). Foam sizing-the performance characteristics of foaming. Journal of China Textile University, 14(4), 1-8.

[18] Zhou X., Zhang S. (1999). The research of foam sizing. Journal of zhejiang college of engineering, 16(3), 166-171.

[19] Gao W. D., Fan X. R., Liu J. L., Zhang J. X., Du L. X. (2014). Technology Study of Foam Sizing. Cotton Textile Technology, 42(9), 1-5.

[20] Lu Y. Z., Zhang J. X., Liu J. L., Gao W. D. (2014). Sizing effects of foam-sizing and yarn pre-wetting combined process. Journal of Textile Research, 12(35), 47-51. 